\title{
Drying duration and stream characteristics influence macroinvertebrate survivorship within the sediments of a temporary channel and exposed gravel bars of a connected perennial stream
}

\author{
Atish N. Vadher · Jonathan Millett • Rachel Stubbington • Paul J. Wood
}

Received: 21 June 2017/Revised: 22 January 2018/Accepted: 27 January 2018/Published online: 19 February 2018

(C) The Author(s) 2018. This article is an open access publication

\begin{abstract}
Intermittent rivers, which experience periods of flow cessation and streambed drying, occur globally. Given that the frequency and duration of stream drying events is likely to increase as a result of anthropogenic pressures and global climate change, riverbed sediments may become increasingly important as refuge habitat for benthic macroinvertebrates. Our study examined the effect of surface water loss and increasing drying duration on the survivorship of the most abundant benthic invertebrate, Gammarus pulex (L.) (Amphipoda: Gammaridae), inhabiting the wet subsurface sediments of exposed gravel bars within a perennial stream and a connected temporarily flowing side channel. G. pulex survivorship declined more over time during drying conditions compared to control conditions (flowing water present).
\end{abstract}

Handling editor: María del Mar Sánchez-Montoya

A. N. Vadher $(\varangle) \cdot$ J. Millett · P. J. Wood

Department of Geography, Centre for Hydrological and

Ecosystem Sciences, Loughborough University,

Loughborough, Leicestershire LE11 3TU, UK

e-mail: A.Vadher@Lboro.ac.uk

A. N. Vadher

Faculty of Arts, Science and Technology, University of Northampton, Avenue Campus, Northampton NN2 6JD, UK

R. Stubbington

School of Science and Technology, Nottingham Trent University, Clifton Campus, Nottingham NG11 8NS, UK
Survivorship was greater in the temporary channel and may reflect the greater water retention capacity of fine sediments in the subsurface and abiotic stability compared to the free-draining exposed gravel bars on the main channel. Our results illustrate that saturated subsurface sediments may facilitate G. pulex persistence during surface drying events and highlight the need for effective refuge management and conservation for instream fauna during drying events.

Keywords Intermittent river - Streambed drying · Dry period · Hyporheic refuge · Faunal survival · Gammarus pulex

\section{Introduction}

Intermittent rivers experience periods of surface flow cessation and typically the drying of some or all of the river bed (Bogan et al., 2015; Datry et al., 2016). These streams comprise a large proportion of the total channel length across the globe, occurring throughout climatic zones from the poles to the equator (Leigh et al., 2016a), making a significant contribution to regional biodiversity (Stubbington et al., 2017), but have typically been overlooked and excluded from national and international legislation protecting streams from anthropogenic degradation (Acuña et al., 2014, 2017). In some instances, historically perennial streams now experience intermittent flow 
and channel drying due to anthropogenic activities such as water abstraction, which captures some or all of the surface flow (Mackay et al., 2014; Arroita et al., 2017). The frequency and duration of 'no-flow' and streambed drying events may increase in some global regions based on future climate change predictions (Bonada et al., 2007a; Verdonschot et al., 2010; Ledger \& Milner, 2015; Pyne \& Poff, 2017), therefore, a greater understanding of the response of lotic ecosystems to drying duration would help guide future management options.

Drying events are typically conceptualised as 'ramp' disturbances which intensify over time as environmental conditions become increasingly unfavourable for the majority of organisms (Lake, 2011). However, the biotic response to drying events and recovery may be characterised by 'stepped' changes in faunal diversity and abundance as critical thresholds of habitat connectivity are transcended (Boulton, 2003; Bogan et al., 2015). Drying events typically result in major changes to instream communities (Leigh et al., 2016b), most notably the loss of rheophilic (Graeber et al., 2013) and desiccationsensitive taxa (Bogan \& Lytle, 2011; Storey, 2016). Drying events may, therefore, be the primary driver of community structure and functioning in intermittent streams (Poff et al., 1997; Bunn \& Arthington, 2002; Leigh \& Datry, 2017). As a result, there is a need to quantify the effects of stream drying on population structure and functioning in lotic ecosystems (Dewson et al., 2007).

The ability of fauna to persist during drying events may be achieved through behavioural adaptations, for example physiological adaptation such as desiccationtolerant juvenile or adult life stages (Strachan et al., 2015; Stubbington et al., 2016), tolerance of declining water quality as discharge declines (van Vilet \& Zwolsman, 2008; Whitworth et al., 2012) and burrowing below the riverbed surface into the saturated subsurface sediments of the hyporheic zone (Stubbington, 2012; Vander Vorste et al., 2016a); the hyporheic zone represents the temporal and spatially dynamic saturated transition zone between surface and groundwater bodies (Krause et al., 2011). Changes to lotic ecosystems associated with stream drying generally include increased conductivity as a result of the concentration of solutes due to evaporation (e.g. Caruso, 2002) and decreased dissolved oxygen (e.g. Boulton \& Lake, 1992; Sprague, 2005). Adaptation to drying enhances community and population resistance (ability to persist during an event) and resilience (ability to recover after flows resume) (Lake, 2000; Bogan et al., 2015) and are widely reported in intermittent streams (Leigh et al., 2016b).

Subsurface sediments have been demonstrated to function as a refuge for invertebrate fauna during drying events by both field studies (Hose et al., 2005; Fenoglio et al., 2006; Vander Vorste et al., 2016a) and laboratory investigations (Vadher et al., 2015; Vander Vorste et al., 2016b) encompassing both intermittent streams and those subject to severe low flows where part of the channel bed (e.g. marginal gravel bars) maybe exposed (Holzapfel et al., 2017). Drying and dewatering of marginal habitats and topographic high points on the channel bed may occur in both intermittent and perennial rivers and benthic fauna have been recorded in both during periods of low flow and complete surface water loss (Wood et al., 2010; Boon et al., 2016). Following the resumption of surface flow, these sediments can be the primary source of stream recolonists, if individuals persist and migrate back to the surface sediments (Vander Vorste et al., 2016a). A range of studies have examined the effect of dry periods and flow permanence (perennial, intermittent and ephemeral streams) on community structure, often demonstrating that different dry phase duration controls community composition (e.g. Feminella, 1996; Bonada, 2007b; Arscott et al., 2010; Datry, 2012; Storey, 2016); although knowledge regarding the effects of stream drying on individual populations remains limited (but see Vander Vorste et al., 2017). In a number of studies amphipod crustaceans have been identified as keystone species and where suitable subsurface sediments exist can migrate from benthic to subsurface habitats (e.g. Wood et al., 2010; Poznańska et al., 2013). They are therefore a potential model group for studying the effects of varying water levels in the subsurface as a stream channel dries.

Gammarus pulex (L.) (Amphipoda: Gammaridae) is a predominantly benthic organism widespread across much of north-western Europe (Crane, 1994; MacNeil et al., 1997). Where abundant, G. pulex is an ecologically important crustacean due to its role in processing coarse particulate organic matter (Navel et al., 2010), as a predator of other invertebrates (Kelly et al., 2006), and as a prey for predatory invertebrates, fish and birds (MacNeil et al., 1997; Kelly et al., 2002). $G$. pulex occurs in the benthic and hyporheic 
sediments of perennial and intermittent streams (Stubbington et al., 2009; Wood et al., 2010), migrating into the subsurface sediments in response to increased predation pressure (McGrath et al., 2007) and channel drying (Vander Vorste et al., 2016a; Vadher et al., In review). Given the key role that amphipods potentially play in the functioning of the hyporheic zone in both perennial and intermittent streams (Vander Vorst et al., 2016b), they are ideal organisms to use in field and laboratory mesocosm studies to address questions around the mechanisms by which fauna persist in streams experiencing surface water loss for varying periods of time. They are also valuable for studies quantifying survivorship associated with the increasing duration of stream drying. These issues are especially relevant given the predictions of increased stream drying and extreme drought events in the future (Ledger \& Milner, 2015; Pyne \& Poff, 2017).

In this study, we examined the effect of increasing duration of surface water loss (drying) on the survivorship of G. pulex using mesocosms within the bed of two adjacent $100 \mathrm{~m}$ long channels of a temperate zone stream comprising i) a temporary flowing channel, and ii) exposed gravel bars of a perennially flowing channel (see Fig. 1). Our aim was to address the following research questions using a mesocosm approach: (1) to what extent does the duration of surface drying (1,2 and 3 weeks) in intermittent streams affect G. pulex survivorship within saturated subsurface sediments? (2) To what extent do abiotic parameters (including subsurface water level and electrical conductivity) affect $G$. pulex survivorship within saturated subsurface sediments during 1,2 and 3 weeks of surface drying.

\section{Materials and methods}

Study site

Black Brook is a small regulated stream located west of Loughborough (Leicestershire, UK). The study sites were located $950 \mathrm{~m}$ downstream of Black Brook reservoir $\left(52^{\circ} 45^{\prime} 53.1^{\prime \prime} \mathrm{N} 1^{\circ} 19^{\prime} 16.8^{\prime \prime} \mathrm{W}\right)$ where the channel divides into two parallel branches, each approximately $3 \mathrm{~m}$ wide (Fig. 1). The primary channel sustains perennial flow and the secondary channel is subject to intermittent flow, experiencing complete streambed drying during base flow conditions. In the perennial channel, marginal gravel bars are exposed as discharge declines. This allowed the investigation of the effect of increasing duration of drying on faunal survival within the saturated sediments of both exposed gravel bars of the perennial channel and within the temporary channel (Fig. 1). Both channels were shaded by deciduous trees and drained pastoral agricultural land.

Preliminary surveys were conducted to quantify the sediment composition and organic matter content of

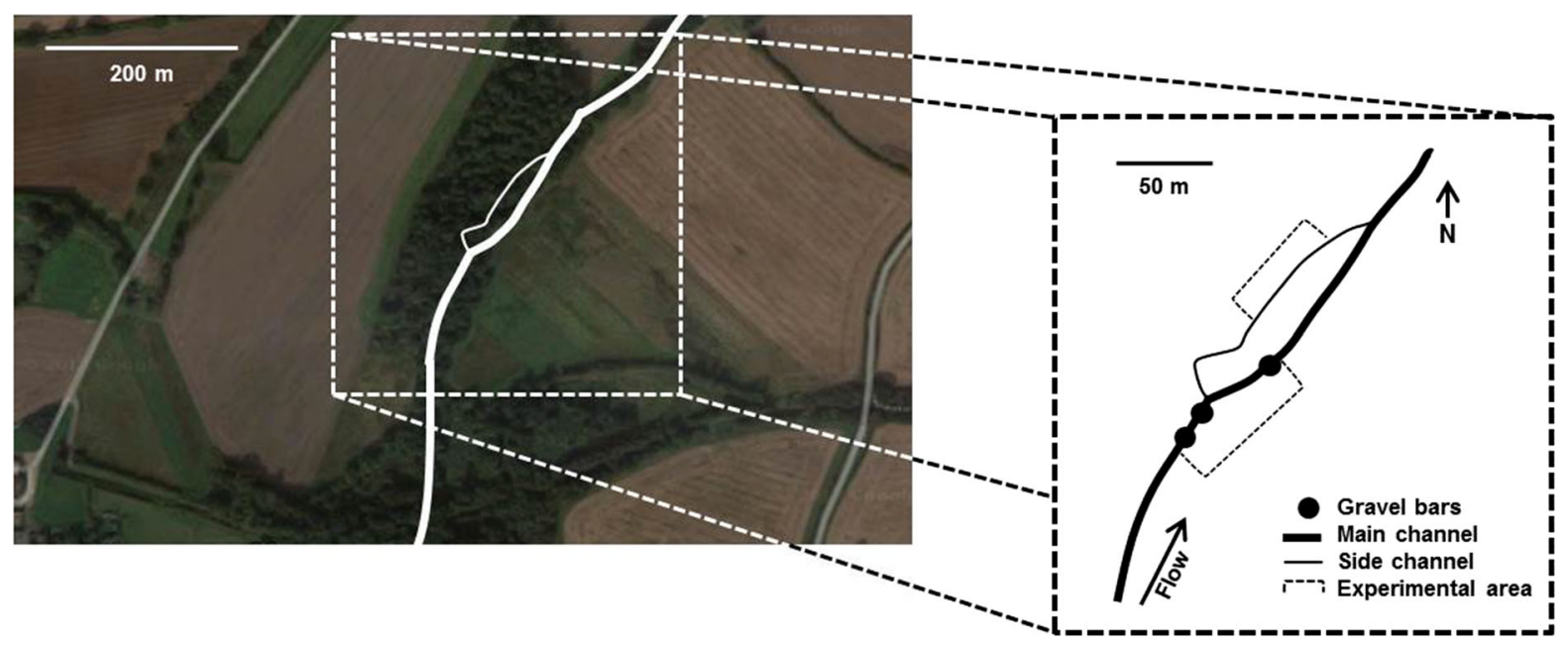

Fig. 1 Diagram of the Black Brook study sites. The experimental area in the perennial channel (containing three gravel bars) and the temporary channel are shown 
both channels. The substrate of both channels was sampled five times in representative areas using a McNeil sampler (McNeil \& Ahnell, 1964), indicating that the subsurface sediments were primarily composed of cobble-gravel-sized clasts: $90.2 \%$ in the perennial channel and $79.7 \%$ in the temporary channel. The proportion of fine sediment $(<2 \mathrm{~mm})$ comprised $9.8 \%$ in the perennial channel and $20.3 \%$ in the temporary channel. Particulate organic matter content was $14.4 \%$ in the perennial channel and $17.8 \%$ in the temporary channel.

Subsurface mesocosm description and installation

Open-ended PVC pipe sections $(6.8 \mathrm{~cm}$ internal diameter $\times 25 \mathrm{~cm}$ length) were used as subsurface columns to house mesocosms constructed using mesh bags (adapted from Mathers \& Wood, 2016). Columns were open-ended to allow movement of downwelling and upwelling water, and perforated with $160.6 \mathrm{~cm}$ diameter holes to allow subsurface water to flow through the columns horizontally (Fig. 2). The columns were inserted to a depth of $25 \mathrm{~cm}$ into the streambed by driving a steel pipe $(6 \mathrm{~cm}$ diameter $)$ vertically into the sediment and threading a column over the pipe and into the subsurface (Fig. 2). The steel pipe was then extracted, leaving a subsurface void within the columns (Fig. 2).

Twelve columns were inserted at the margin of each of three submerged gravel bars $(n=36)$ in the perennial channel (Fig. 1) with $\geq 50 \mathrm{~cm}$ between each to avoid any influence of adjacent columns

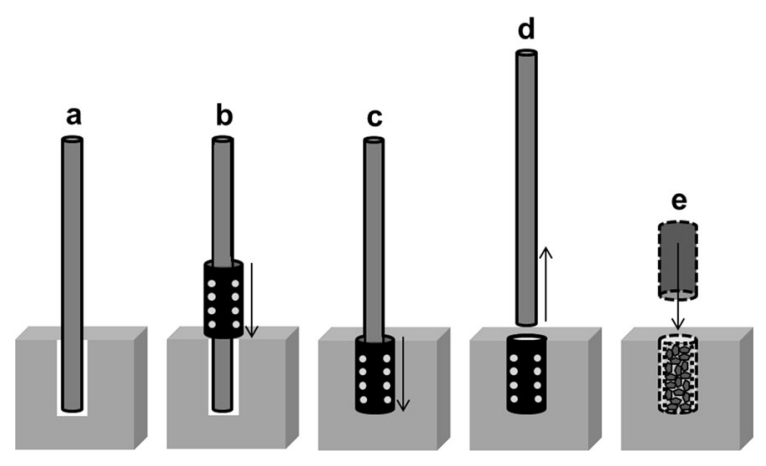

Fig. 2 Schematic diagram of subsurface column installation. a Steel pipe $(6 \mathrm{~cm}$ diameter) driven $25 \mathrm{~cm}$ into the streambed; b subsurface column thread over the pipe; c column driven into the streambed around the pipe; $\mathbf{d}$ pipe removed leaving the column in place; e blank sediment bag inserted into subsurface column. Not to scale during installation and the experiments. A total of 36 subsurface columns were also inserted into the temporary channel, $\geq 50 \mathrm{~cm}$ apart (Fig. 1). To allow the sediment matrix around the columns to settle and to avoid the subsurface voids created by the columns filling with fine sediment, mesh bags $(0.5 \mathrm{~cm}$ aperture mesh) containing medium-sized gravel were inserted into the columns until the experiment commenced, when they were replaced by the experimental mesocosms.

The mesocosms (mesh bags) were constructed from $60 \mathrm{~cm}^{2}$ sections of $250 \mu \mathrm{m}$ aperture mesh. Each mesocosm was filled with medium-sized gravel particles (10-20 mm size range) and mixed pre-conditioned native leaf litter from the channel upstream. These leaves were rinsed in stream water and visually inspected to ensure any fauna present were removed prior to their use. G. pulex were collected from a riffle $>200 \mathrm{~m}$ upstream of the study sites using a standard kick net $(1 \mathrm{~mm}$ mesh, $230 \mathrm{~mm} \times 255 \mathrm{~mm}$ frame, $275 \mathrm{~mm}$ bag depth) and 10 individuals ( $>5 \mathrm{~mm}$ in size) were placed into each mesocosm. Ten individuals per mesocosm represents a low population density of G. pulex at this site to reduce any effect of cannibalism (McGrath et al., 2007) on survivorship within the subsurface in response to surface water loss. Each mesocosm was securely sealed with a cable tie to contain the contents throughout the experiment.

To examine the effect of drying duration, mesocosms were left in situ for 7, 14 or 21 days during both flowing (control) conditions and during drying of the marginal gravel bars and temporary channel. The experimental period took place between the end of May and early September 2015 on the declining limb of the hydrograph. Given that the temporary channel and perennial stream gravel bars did not experience surface water loss at exactly the same time, control and drying experiments were conducted when the conditions were appropriate in each channel. Twelve replicate mesocosms $\times 3$ durations $\times 2$ conditions $\times 2$ channels yielded a total of 144 mesocosms.

At the end of the experimental period ( 7,14 or 21 days), mesocosms were extracted from subsurface columns and submerged into a container of stream water for immediate transport to the laboratory for determination of survivorship. To examine variability in abiotic parameters, we measured-dissolved oxygen (using a dissolved oxygen meter, Hanna 
Instruments HI-9142), $\mathrm{pH}$ and temperature (using a handheld $\mathrm{pH} /$ temperature tester, Hanna Instruments pHep®4 HI-98127), conductivity (using a handheld conductivity sensor, Hanna Instruments HI-98311), and water level from the surface of the sediment. These were measured in situ in the free water within subsurface columns before and after mesocosms were deployed.

\section{Laboratory assessment of G. pulex survivorship}

The contents of individual mesocosms were carefully placed into a large white tray containing stream water, inspected, and survivorship determined by counting the number of live (active) G. pulex present. Inactive whole and parts of $G$. pulex individuals were recorded as dead, and absent G. pulex were assumed to have been cannibalised (McGrath et al., 2007) or decomposed as a result of stranding above the waterline. Individual body parts were not counted unless the head was observed.

\section{Statistical analysis}

A General Linear Model (GLM) was used to examine the effect of experiment condition (flowing surface water/surface drying), experiment duration (7, 14 and 21 days) and site (temporary channel/marginal gravel bars) on G. pulex survivorship using a full-factorial 3-way combination of these factors, with each as a fixed effect. Post hoc Fisher's Least Significant Difference tests were used to examine the effect of duration on G. pulex survivorship. A second GLM was used to determine the influence of these factors (condition, duration and site main effects) plus the change (start vs. end) in abiotic parameters $(\mathrm{pH}$, dissolved oxygen, water temperature, conductivity and water level) defined as covariates on G. pulex survivorship. A third multivariate GLM was used to compare the mean abiotic parameters (defined as dependent variables) between the two sites (defined as a fixed factor). A final multivariate GLM was used to compare the mean abiotic parameters (dependent variables) between each duration and condition (fixed factors) within each site. The significance level used for all tests was 0.05. All analyses were conducted in IBM SPSS Statistics (version 23, IBM Corporation, New York).

\section{Results}

Abiotic parameter variability

Water level was lower during the drying experiments compared to the control conditions in both the temporary channel and marginal gravel bars (Table 1). Water level (GLM, $F_{1,142}=4.213, P=0.042$ ), $\mathrm{pH}$ $\left(F_{1}, \quad 142=166.584, P<0.001\right)$, dissolved oxygen $\left(F_{1,142}=14.558, P<0.001\right)$ and water temperature $\left(F_{1,142}=121.712, P<0.001\right)$ were lower, and mean conductivity $\left(F_{1}, 142=603.017, P<0.001\right)$ was higher, in the temporary channel compared to the gravel bars of the perennial channel (Table 1). Within the temporary channel, $\mathrm{pH}$ (GLM, $F_{1,68}=13.274$, $P=0.001)$ and dissolved oxygen $\left(F_{1,68}=85.609\right.$, $P<0.001)$ were higher during drying conditions, and the mean $\mathrm{pH}\left(F_{2,68}=12.690, P<0.001\right)$, dissolved oxygen $\left(F_{2}, 68=4.582, P=0.014\right)$, temperature $\left(F_{2}, \quad 68=16.398, \quad P<0.001\right) \quad$ and conductivity $\left(F_{2}, \quad 68=6.515, \quad P=0.003\right) \quad$ displayed varied responses to experiment duration (Table 1). Within the gravel bars, $\mathrm{pH}$ (GLM, $F_{1,68}=32.4, P<0.001$ ), dissolved oxygen $\left(F_{1,68}=24.375, P<0.001\right)$ and temperature $\left(F_{1,68}=63.914, P<0.001\right)$ decreased during the drying conditions whereas mean conductivity $\left(F_{1,68}=25.382, P<0.001\right)$ increased. Mean $\mathrm{pH}\left(\mathrm{GLM}, F_{2,68}=6.33, P=0.003\right)$ and dissolved oxygen $\left(F_{1,68}=6.569, P=0.002\right)$ showed a mixed response to experiment duration in the gravel bars (Table 1).

The effects of change in abiotic parameters on the survivorship of G. pulex

Survivorship of $G$. pulex was not associated with changes in $\mathrm{pH}\left(\mathrm{GLM}, F_{1}, 134=0.37, P=0.554\right)$, dissolved oxygen $\left(F_{1}, 134=2.001, P=0.159\right)$ or water temperature $\left(F_{1}, \quad 134=0.207, \quad P=0.650\right)$ recorded during control or drying experiments. However, survivorship of $G$. pulex was reduced when surface water was absent (only subsurface water was present in the saturated sediments) (GLM, $\left.F_{1,134}=5.230, P=0.024\right)$ and at higher conductivities $\left(F_{1}, 134=9.399, P=0.008\right)$. In the temporary channel, conductivity remained stable over the 7-, 14and 21-day experiments for both control and drying conditions (Table 1). In contrast, the conductivity recorded in marginal gravel bars was higher during the 
Table 1 Mean $( \pm \mathrm{SE}) \mathrm{pH}$, dissolved oxygen, water temperature, conductivity and water level after each experiment duration in the temporary channel and marginal gravel bars of the perennial channel during (a) control (surface water present) and (b) surface drying conditions

\begin{tabular}{|c|c|c|c|c|c|c|}
\hline \multirow[t]{3}{*}{ Mean parameter } & \multicolumn{3}{|c|}{ Temporary channel } & \multicolumn{3}{|c|}{ Marginal gravel bars } \\
\hline & \multicolumn{3}{|c|}{ Duration (days) } & \multicolumn{3}{|c|}{ Duration (days) } \\
\hline & 7 & 14 & 21 & 7 & 14 & 21 \\
\hline \multicolumn{7}{|l|}{ (a) Control condition } \\
\hline $\mathrm{pH}$ & $7.6 \pm 0.0$ & $7.6 \pm 0.0$ & $7.6 \pm 0.0$ & $8.2 \pm 0.0$ & $8.3 \pm 0.0$ & $8.2 \pm 0.0$ \\
\hline Dissolved oxygen $\left(\mathrm{mg} \mathrm{l}^{-1}\right)$ & $3.5 \pm 0.2$ & $2.8 \pm 0.1$ & $3.2 \pm 0.2$ & $7.7 \pm 0.1$ & $6.6 \pm 0.2$ & $7.6 \pm 0.2$ \\
\hline Water temperature $\left({ }^{\circ} \mathrm{C}\right)$ & $11.3 \pm 0.1$ & $10.8 \pm 0.0$ & $11.3 \pm 0.1$ & $17.5 \pm 0.0$ & $16.8 \pm 0.0$ & $17.2 \pm 0.0$ \\
\hline Conductivity $\left(\mu \mathrm{S} \mathrm{cm}^{-1}\right)$ & $843 \pm 12.2$ & $861 \pm 2.7$ & $863 \pm 2.7$ & $470 \pm 0.7$ & $485 \pm 5.9$ & $471 \pm 0.5$ \\
\hline Water level (mm) & $35 \pm 8.4$ & $25 \pm 3.9$ & $18 \pm 2.8$ & $75 \pm 5.7$ & $47 \pm 5.1$ & $119 \pm 11.8$ \\
\hline Max. water level (mm) & 110 & 50 & 40 & 110 & 65 & 170 \\
\hline \multicolumn{7}{|l|}{ (b) Surface drying condition } \\
\hline $\mathrm{pH}$ & $7.6 \pm 0.0$ & $7.8 \pm 0.0$ & $7.7 \pm 0.0$ & $7.8 \pm 0.6$ & $7.9 \pm 0.4$ & $7.8 \pm 0.7$ \\
\hline Dissolved oxygen $\left(\mathrm{mg}^{-1}\right)$ & $4.6 \pm 0.3$ & $4.3 \pm 0.3$ & $4.9 \pm 0.2$ & $3.4 \pm 0.7$ & $4.6 \pm 0.8$ & $2.5 \pm 0.4$ \\
\hline Water temperature $\left({ }^{\circ} \mathrm{C}\right)$ & $11 \pm 0.0$ & $10.9 \pm 0.1$ & $11 \pm 0.0$ & $11.7 \pm 0.9$ & $11.9 \pm 0.8$ & $14.3 \pm 0.3$ \\
\hline Conductivity $\left(\mu \mathrm{S} \mathrm{cm}^{-1}\right)$ & $850 \pm 1.7$ & $852 \pm 2.6$ & $852 \pm 1.8$ & $711 \pm 27.8$ & $637 \pm 32.4$ & $666 \pm 37.7$ \\
\hline Water level $(\mathrm{mm})$ & $-19 \pm 4.5$ & $-8 \pm 3.5$ & $-24 \pm 5.4$ & $-29 \pm 9.4$ & $-33 \pm 11.0$ & $-24 \pm 6.1$ \\
\hline Min. water level (mm) & -50 & -40 & -50 & -105 & -95 & -85 \\
\hline
\end{tabular}

drying experiments compared to control conditions (Table 1).

Effect of drying, drying duration and site on G. pulex survivorship

Surface drying reduced the survivorship of G. pulex in comparison to experiments in which surface water was present (Table 2; Fig. 3a). An increase in experiment duration reduced $G$. pulex survivorship during both control and drying conditions and in both the temporary channel and marginal gravel bars (Table 2; Fig. 3). G. pulex survivorship was higher in the temporary channel compared to the marginal gravel bars (Table 2; Fig. 3b). For each duration, survivorship was higher during control conditions compared to the drying conditions, in both the temporary channel ( 7 days, GLM, $F_{1,22}=16.298, P=0.001 ; 14$ days, $F_{1,22}=19.366, P<0.001 ; 21$ days, $F_{1,22}=18.140$, $P<0.001$; Fig. 4$)$ and in the gravel bars (7 days, GLM $, \quad F_{1}, \quad 22=5.301, \quad P=0.031 ; \quad 14$ days, $F_{1}, \quad 22=4.758, \quad P=0.040 ; \quad F_{1}, \quad 22=7.152$, $P=0.014$, Fig. 4).
Table 2 Full-factorial 3-way general linear model (GLM) analysis for the effect of condition (flowing surface water/surface drying), duration (7, 14, 21 days) and site (temporary channel/marginal gravel bars) on Gammarus pulex survivorship

\begin{tabular}{llrr}
\hline Fixed factors & $d f$ & \multicolumn{1}{l}{$F$} & \multicolumn{1}{l}{$P$} \\
\hline Main effects & & & \\
$\quad$ Condition & 1 & 53.510 & $<\mathbf{0 . 0 0 1}$ \\
Duration & 2 & 5.907 & $\mathbf{0 . 0 0 3}$ \\
Site & 1 & 19.102 & $<\mathbf{0 . 0 0 1}$ \\
2-way & & & \\
Condition $\times$ Duration & 2 & 0.159 & 0.853 \\
Condition $\times$ Site & 1 & 0.104 & 0.748 \\
$\quad$ Duration $\times$ Site & 2 & 1.640 & 0.198 \\
3-way & & & \\
$\quad$ Duration $\times$ Site $\times$ Condition & 2 & 0.701 & 0.498 \\
\hline
\end{tabular}

Significant values are emboldened 

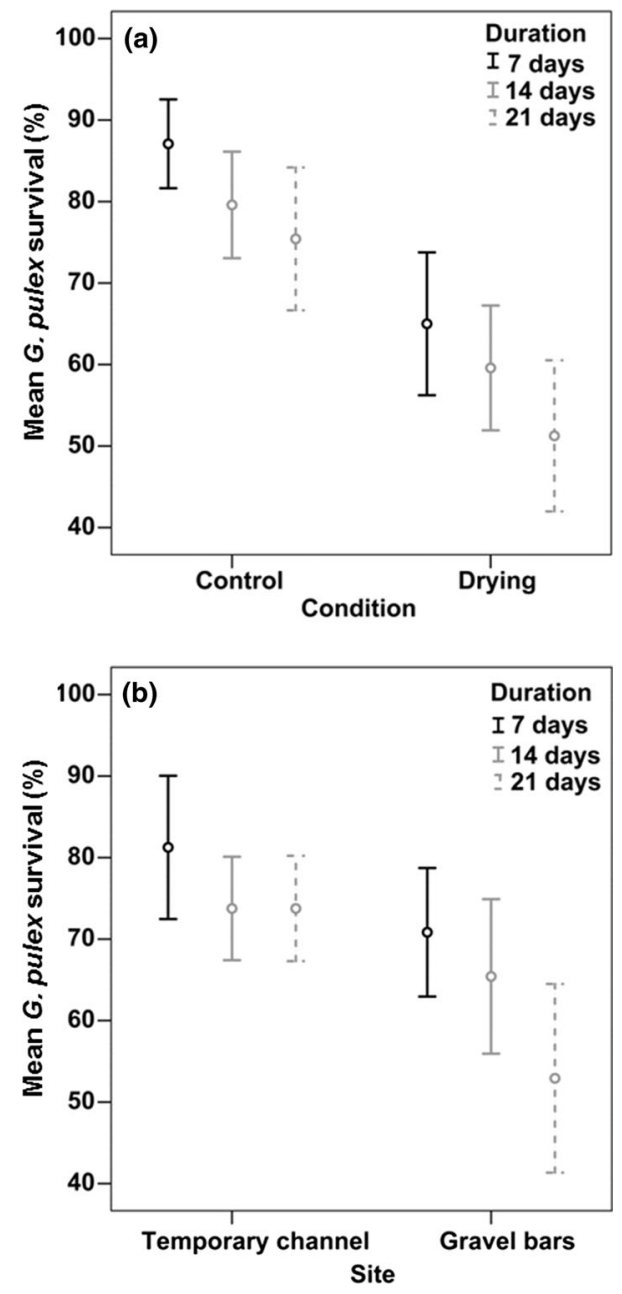

Fig. 3 Mean \pm 2 SE percentage survival of Gammarus pulex in each experiment duration (7, 14 and 21 days) in (a) flowing (control) and surface drying experimental conditions; and (b) sites in a temporary channel and in exposed gravel bars of a perennial channel. $Y$ axes start at $40 \%$

\section{Discussion}

Surface water loss and increasing duration of stream drying reduced G. pulex survivorship within the wet subsurface sediments

Our study, examined channels that regularly experience a reduction in surface flow which facilitated an experimental approach to examine the effect of drying and duration of surface drying in the field. We found that $G$. pulex survivorship within saturated subsurface mesocosms was reduced by around $20 \%$ when channel surface drying occurred compared to locations at
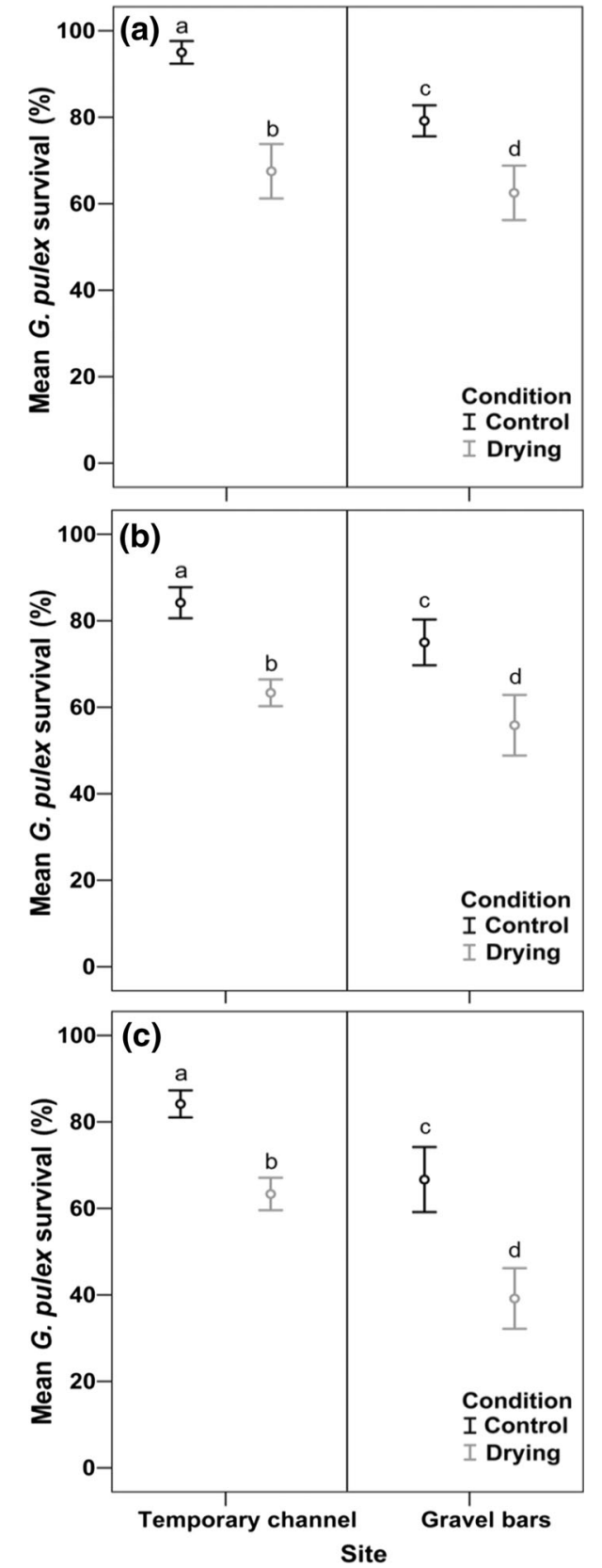

Fig. 4 Mean ( $\pm 1 \mathrm{SE}$ ) percentage survival of Gammarus pulex in each duration for control and drying experiments within each site (temporary channel and exposed gravel bars): a 7 days, b 14 days, c 21 days. Letters ' $a$ ' to ' $d$ ' represent values that are significantly different within the temporary channel and gravel bars $(\mathrm{GLM}, P<0.05)$

which surface water persisted. We also found that an increasing period of surface drying duration reduced survivorship within wet subsurface sediments by 
$7-10 \%$ between 7 and 14 days and 14 and 21 days, respectively. Previous research has reported reduced survivorship of common benthic invertebrates such as gammarids due to surface water loss in the surface (e.g. Poznańska et al., 2013) and subsurface (Vander Vorste et al., 2016b) sediments, and field investigations have reported reduced abundance of individuals with increasing intermittence (Clarke et al., 2010; Datry et al., 2014a) and duration of surface drying events (Storey, 2016). The majority of G. pulex individuals survived within the wet subsurface for periods of surface water loss $<21$ days, indicating that wet subsurface sediments can facilitate population persistence during short-term surface drying events. These experimental observations support field studies (predominantly based on hyporheic sampling) which indicate that wet subsurface sediments form an important refuge for macroinvertebrates during streambed drying events (Hose et al., 2005; Fenoglio et al., 2006; Vander Vorste et al., 2016a).

It has been widely acknowledged that an increase in the duration of channel drying events may result in the degradation of lotic ecosystem communities (Lake, 2003; Datry, 2012). In the absence of the input of groundwater or rainfall (precipitation) subsurface water levels and sediment moisture content normally declines with increasing drying duration. This may reduce the persistence of biota at both the population and community level within subsurface sediments (Stubbington et al., 2009; Stubbington \& Datry, 2013). Our results, reporting the effects on increased drying duration on G. pulex populations, support previous observations of reduced benthic and hyporheic invertebrate community density (Arscott et al., 2010; Datry, 2012; Datry et al., 2014b). Fritz \& Dodds (2004) reported a $50 \%$ reduction in benthic macroinvertebrate community density following a (2-month) drying period compared to an $86 \%$ reduction following a longer (9-month) dry period at intermittent sites over 2-year study. The study sites of the current study had comparable subsurface sediments (gravels and cobbles) to those reported by Fritz \& Dodds (2004), but the shallow bedrock and packed clay in the subsurface resulted in a hyporheic zone that completely dried in the latter. Given the inherent heterogeneity of streambed sediments, the wider application of mesocosms in field experiments may be particularly useful for quantifying taxon-specific responses to drying by controlling for natural spatial heterogeneity of sedimentary characteristics and via their deployment over standard time periods (e.g. Gayraud \& Philippe, 2003; Navel et al., 2010).

Declining water level and variable conductivity reduced G. pulex survivorship

within the subsurface sediments

The retention of water in subsurface sediments is a key determinant of macroinvertebrate survivorship in channels subject to surface water drying (Hose et al., 2005; Chester \& Robson, 2011). In the current study, water level never declined below the base of the mesocosms and this illustrates that fully saturated interstices (retention of free water) can support macroinvertebrate persistence for longer, whereas moist interstices (reduced free water) have been shown to facilitate persistence of $G$. pulex for shorter durations (up to 7 days-Stubbington et al., 2009). In addition, the temporary channel had higher organic matter and fine sediment contents compared to the gravel bars, potentially reducing interstitial flow (Greig et al., 2005) and facilitating moisture retention within benthic sediments (Strachan et al., 2014). Our field observations indicate that fully saturated conditions in the subsurface sediments of the temporary channel (where water level declined by $<50 \mathrm{~mm}$ on average) resulted in more stable abiotic conditions even during channel drying compared to the abiotic variability recorded within the saturated subsurface sediments of the exposed gravel bars at the margin of a perennially flowing stream. These results suggest a positive relationship between reduced variability in subsurface habitat conditions (e.g. depth to saturated subsurface sediments) and enhanced survivorship of G. pulex. Information regarding the stability and variability of saturated subsurface habitats within the hyporheic zone and its influence on faunal populations may enable river managers to identify and protect areas of the channels bed that may serve as refuge during stream drying events.

Channel surface water drying reduced the survivorship of G. pulex in subsurface sediments. This suggests that survivorship of individuals within the mesocosms was reduced due to stranding above the free water and supports the findings of other studies (e.g. Navel et al., 2010; Vadher et al., 2015; Vander Vorste et al., 2016b). Vadher et al. (2017) demonstrated the importance of sedimentology on the ability of G. pulex to 
move vertically through sediments. Considering the gravel particles used in the present experiment (medium gravel-10-20 $\mathrm{mm}$ in diameter), most $G$. pulex should have been able to move vertically and avoid stranding (Vadher et al., 2017) suggesting that in this field experimental duration and abiotic parameters, but not sediment size, affected survivorship. However, our own laboratory mesocosm studies have demonstrated that particle shape, size and its resultant effect of porosity also strongly influence the ability of G. pulex and other taxa to move vertically within subsurface sediments (Vadher et al., 2017) in response to surface drying. This knowledge should be incorporated into the design of future field investigations to enable the effect of sedimentological variability to be quantified.

Conductivity increased significantly, by at least $150 \mu \mathrm{S} \mathrm{cm}^{-1}$ up to $711 \mu \mathrm{S} \mathrm{cm}{ }^{-1}$ (Table 1), in the subsurface of exposed gravel bars during drying conditions, reflecting the increased residence time of water and increased contribution of solutes from groundwater due to reduced dilution by surface water as levels in the stream declined (Caruso, 2002; Acuña et al., 2005; Sprague, 2005). Mathers et al. (2017) reported comparable conductivity values on Black Brook to those recorded in control treatments on gravel bars in this study, indicating values were elevated in the temporary channel, and during drying in both channels in this study. Both the reduction in water level and increase in conductivity may have reduced G. pulex survivorship compared to the temporary channel, which experienced a reduced magnitude of change in water level and conductivity. Previous research has reported elevated conductivity during drying events when examining the effects of water quality changes on macroinvertebrate communities (Caruso, 2002; Ferreira et al., 2014; Verdonschot et al., 2015). However, conductivity was within the typical tolerance range reported for $G$. pulex (e.g. Piscart et al., 2011) and the highest levels were recorded in the temporary channel where survivorship was greatest. These results illustrate that the direct effect of increasing conductivity during drying events on the survival of macroinvertebrates is poorly understood.
Conclusions and future directions

Drying events are likely to increase in frequency and duration in some regions of the globe as a result of climate change (Forzieri et al., 2014; Ledger \& Milner, 2015; Pyne \& Poff, 2017) and increasing pressure on water resources (Arroita et al., 2017). This study highlights the effect of surface water loss and increasing dry period duration on the survivorship of the common benthic macroinvertebrate $G$. pulex within saturated subsurface sediments. However, knowledge regarding the effect of stream drying duration on other taxa remains limited and requires detailed investigation. This research also highlights the need for effective river management to maintain subsurface sediment moisture and porosity to provide a viable refuge and promote population persistence during short periods of drying (Vander Vorste et al., 2016a; Vadher et al., 2017), particularly in nearperennial temperate zone streams with perennial communities exposed to day-to-week long drying events. Future research building on existing knowledge (e.g. Capderrey et al., 2013; Mermillod-Blondin et al., 2015) should seek to determine the characteristics of sediments with a high potential to serve as a refuge during drying. Future research should also use field-based mesocosm experiments to improve understanding into the effect of longer drying durations in streams from individuals and populations through to the community level. Such experiments should encompass the recovery of aquatic fauna after surface water returns to further understanding into drying persistence and recolonization processes.

Acknowledgements ANV gratefully acknowledges the Loughborough University, School of Social, Political and Geographical Sciences studentship for funding this work. We acknowledge the outstanding field and lab assistance of Rajpal S. Matharu and Nimish N. Vadher in the construction, installation and collection of mesocosms. We also acknowledge the field assistance of Jaspreet Bahia, Davinder S. Gill, Kate Mathers and Anish N. Vadher. We thank Kate Mathers for her advice on the analyses. We thank Richard Harland for help in constructing the mesocosms. We thank Associate Editor María Mar Sánchez Montoya and two anonymous reviews for their comments which improved the clarity and quality of this paper.

Open Access This article is distributed under the terms of the Creative Commons Attribution 4.0 International License (http:// creativecommons.org/licenses/by/4.0/), which permits unrestricted use, distribution, and reproduction in any medium, 
provided you give appropriate credit to the original author(s) and the source, provide a link to the Creative Commons license, and indicate if changes were made.

\section{References}

Acuña, V., I. Muñoz, A. Giorgi, M. Omella, F. Sabater \& S. Sabater, 2005. Drought and postdrought recovery cycles in an intermittent Mediterranean stream: structural and functional aspects. Journal of the North American Benthological Society 24: 919-933.

Acuña, V., T. Datry, J. Marshall, D. Barceló, C. N. Dahm, A. Ginebreda, G. McGregor, S. Sabater, K. Tockner \& M. A. Palmer, 2014. Why should we care about temporary waterways? Science 343: 1080-1081.

Acuña, V., M. Hunter \& A. Ruhí, 2017. Managing temporary streams and rivers as unique rather than second-class ecosystems. Biological Conservation 211: 12-19.

Arroita, M., L. Flores, A. Larrañag, A. Martínez, M. MartínezSantos, O. Pereda, E. Ruiz-Romera, L. Solagaistua \& A. Elosegi, 2017. Water abstraction impacts stream ecosystem functioning via wetted-channel contraction. Freshwater Biology 62: 243-257.

Arscott, D. B., S. T. Larned, M. R. Scarsbrook \& P. Lambert, 2010. Aquatic invertebrate community structure along an intermittency gradient: Selwyn River, New Zealand. Journal of the North American Benthological Society 29: $530-545$.

Bogan, M. T. \& D. A. Lytle, 2011. Severe drought drives novel community trajectories in desert stream pools. Freshwater Biology 56: 2070-2081.

Bogan, M. T., K. S. Boersma \& D. A. Lytle, 2015. Resistance and resilience of invertebrate communities to seasonal and supraseasonal drought in arid-land headwater streams. Freshwater Science 60: 2547-2558.

Bonada, N., S. Dolédec \& B. Statzner, 2007a. Taxonomic and biological trait differences of stream macroinvertebrate communities between Mediterranean and temperate regions: implications for future climatic scenarios. Global Change Biology 13: 1658-1671.

Bonada, N., M. Rieradevall \& N. Prat, 2007b. Macroinvertebrate community structure and biological traits related to flow permanence in a Mediterranean river network. Hydrobiologia 589: 91-106.

Boon, P. J., N. Willby, D. Gilvear \& D. Pryce, 2016. The regional hyporheic fauna of gravel-bed rivers and environmental controls on its distribution. Fundamental and Applied Limnology 187: 223-239.

Boulton, A. J., 2003. Parallels and contrasts in the effects of drought on stream macroinvertebrate assemblages. Freshwater Biology 48: 1173-1185.

Boulton, A. J. \& P. S. Lake, 1992. The ecology of two intermittent streams in Victoria, Australia. II Comparisons of faunal composition between habitats, rivers and years. Freshwater Biology 27: 99-121.

Bunn, S. E. \& A. H. Arthington, 2002. Basic principles and ecological consequences of altered flow regimes for aquatic biodiversity. Environmental Management 30: 492-507.

Capderrey, C., T. Datry, A. Foulquier, C. Claret \& F. Malard, 2013. Invertebrate distribution across nested geomorphic features in braided-river landscapes. Freshwater Science 32: 1188-1204.

Caruso, B. S., 2002. Temporal and spatial patterns of extreme low flows and effects on stream ecosystems in Otago, New Zealand. Journal of Hydrology 257: 115-133.

Chester, E. T. \& B. J. Robson, 2011. Drought refuges, spatial scale and recolonization by invertebrates in non-perennial streams. Freshwater Biology 56: 2094-2104.

Clarke, A., R. Mac Nally, N. Bond \& P. S. Lake, 2010. Flow permanence affects aquatic macroinvertebrate diversity and community structure in three headwater streams in a forested catchment. Canadian Journal of Fisheries and Aquatic Sciences 67: 1649-1657.

Crane, M., 1994. Population characteristics of Gammarus pulex (L.) from five English streams. Hydrobiologia 281: 91-100.

Datry, T., 2012. Benthic and hyporheic invertebrate assemblages along a flow intermittency gradient: effects of duration of dry events. Freshwater Biology 57: 563-574.

Datry, T., S. T. Larned \& K. Tockner, 2014a. Intermittent rivers: a challenge for freshwater ecology. Bioscience 64: 229-235.

Datry, T., S. T. Larned, K. M. Fritz, M. T. Bogan, P. J. Wood, E. I. Meyer \& A. N. Santos, 2014b. Broad-scale patterns of invertebrate richness and community composition in temporary rivers: effects of flow intermittence. Ecography 37 : 94-104.

Datry, T., K. Fritz \& C. Leigh, 2016. Challenges, developments and perspectives in intermittent river ecology. Freshwater Biology 61: 1181-1199.

Dewson, Z. S., A. B. W. James \& R. G. Death, 2007. A review of the consequences of decreased flow for instream habitat and macroinvertebrates. Journal of the North American Benthological Society 26: 401-415.

Ferreira, W. R., R. Ligeiro, D. R. Macedo, R. M. Hughes, P. R. Kaufmann, L. G. Oliveira \& M. Callisto, 2014. Importance of environmental factors for the richness and distribution of benthic macroinvertebrates in tropical headwater streams. Freshwater Science 33: 860-871.

Feminella, J. W., 1996. Comparison of benthic macroinvertebrate assemblages in small streams along a gradient of flow permanence. Journal of the North American Benthological Society 15: 651-669.

Fenoglio, S., T. Bo \& G. Bosi, 2006. Deep interstitial habitat as a refuge for Agabus paludosus (Fabricus) (Coleoptera: Dytiscidae) during summer droughts. Coleopterists Bulletin 60: 37-41.

Forzieri, G., L. Feyen, R. Rojas, M. Flörke, F. Wimmer \& A. Bianchi, 2014. Ensemble projections of future streamflow droughts in Europe. Hydrology and Earth System Sciences 18: 85-108.

Fritz, K. M. \& W. K. Dodds, 2004. Resistance and resilience of macroinvertebrate assemblages to drying and flood in a tallgrass prairie stream system. Hydrobiologia 527: 99-112.

Gayraud, S. \& M. Philippe, 2003. Influence of bed-sediment features on the interstitial habitat available for 
macroinvertebrates in 15 French streams. International Review of Hydrobiology 88: 77-93.

Graeber, D., M. T. Pusch, S. Lorenz \& M. Brauns, 2013. Cascading effects of flow reduction on the benthic invertebrate community in a lowland river. Hydrobiologia 717: 147-159.

Greig, S. M., D. A. Sear \& P. A. Carling, 2005. The impact of fine sediment accumulation on the survival of incubating salmon progeny: implications for sediment management. Science of the Total Environment 344: 241-258.

Holzapfel, P., P. Leitner, H. Habersack, W. Graf \& C. Hauer, 2017. Evaluation of hydropeaking impacts on the food web in alpine streams based on modelling of fish- and macroinvertebrate habitats. Science of the Total Environment 575: 1489-1502.

Hose, G. C., P. Jones \& R. P. Lim, 2005. Hyporheic macroinvertebrates in riffle and pool areas of temporary streams in south eastern Australia. Hydrobiologia 532: 81-90.

Kelly, D. W., J. T. A. Dick \& W. I. Montgomery, 2002. The functional role of Gammarus (Crustacea: Amphipoda): shredders, predators, or both? Hydrobiologia 485: 199-203.

Kelly, D. W., R. J. Bailey, C. MacNeil, J. T. A. Dick \& R. A. McDonald, 2006. Invasion by the amphipod Gammarus pulex alters community composition of native freshwater macroinvertebrates. Diversity and Distributions 12: 525-534.

Krause, S., D. M. Hannah, J. H. Fleckenstein, C. M. Heppell, D. Kaeser, R. Pickup, G. Pinay, A. Robertson \& P. J. Wood, 2011. Inter-disciplinary perspectives on processes in the hyporheic zone. Ecohydrology 4: 481-499.

Lake, P. S., 2000. Disturbance, patchiness, and diversity in streams. Journal of the North American Benthological Society 19: 573-592.

Lake, P. S., 2003. Ecological effects of perturbation by drought in flowing waters. Freshwater Biology 48: 1161-1172.

Lake, P. S., 2011. Drought and Aquatic Ecosystems: Effects and Responses. Wiley, Oxford.

Ledger, M. E. \& A. M. Milner, 2015. Extreme events in running water. Freshwater Biology 60: 2455-2460.

Leigh, C. \& T. Datry, 2017. Drying as a primary hydrological determinant of biodiversity in river systems: a broad-scale analysis. Ecography 40: 487-499.

Leigh, C., N. Bonada, A. J. Boulton, B. Hugueny, S. T. Larned, R. Vander Vorste \& T. Datry, 2016a. Invertebrate assemblage responses and the dual roles of resistance and resilience to drying in intermittent rivers. Aquatic Sciences 78: 291-301.

Leigh, C., A. J. Boulton, J. L. Courtwright, K. Fritz, C. L. May, R. H. Walker \& T. Datry, 2016b. Ecological research and management of intermittent rivers: an historical review and future directions. Freshwater Biology 61: 1181-1199.

Mackay, S. J., A. H. Arthington \& C. S. James, 2014. Classification and comparison of natural and altered flow regimes to support an Australian trial of the ecological limits of hydrologic alteration framework. Ecohydrology 7: 1485-1507.

MacNeil, C., J. T. A. Dick \& R. W. Elwood, 1997. The trophic ecology of freshwater Gammarus spp. (Crustacea: Amphipoda): problems and perspectives concerning the functional feeding group concept. Biological Reviews of the Cambridge Philosophical Society 72: 349-364.

Mathers, K. L. \& P. J. Wood, 2016. Fine sediment deposition and interstitial flow effects on macroinvertebrate community composition within riffle heads and tails. Hydrobiologia 776: 147-160.

Mathers, K. L., M. J. Hill \& P. J. Wood, 2017. Benthic and hyporheic macroinvertebrate distribution within heads and tails of riffles during baseflow conditions. Hydrobiologia 794: 17-30.

McGrath, K. E., E. T. H. M. Peeters, J. A. J. Beijer \& M. Scheffer, 2007. Habitat-mediated cannibalism and microhabitat restriction in the stream invertebrate Gammarus pulex. Hydrobiologia 589: 155-164.

McNeil, W. J. \& W. H. Ahnell, 1964. Success of pink salmon spawning relative to size of spawning bed materials. U.S. Fish and Wildlife Service, Special Scientific Report Fisheries 469: 1-15.

Mermillod-Blondin, F., T. Winiarski, A. Foulquier, A. Perrissin \& P. Marmonier, 2015. Links between sediment structures and ecological processes in the hyporheic zone: groundpenetrating radar as a non-invasive tool to detect subsurface biologically active zones. Ecohydrology 8: 626-641.

Navel, S., F. Mermillod-Blondin, B. Montuelle, E. Chauvet, L. Simon, C. Piscart \& P. Marmonier, 2010. Interactions between fauna and sediment control the breakdown of plant matter in river sediments. Freshwater Biology 55: $753-766$.

Piscart, C., B. J. Kefford \& J. N. Beisel, 2011. Are salinity tolerances of non-native macroinvertebrates in France an indicator of potential for their translocation in a new area? Limnologica 41: 107-112.

Poff, N. L., J. D. Allan, M. B. Bain, J. R. Karr, K. L. Prestegaard, B. D. Richter, R. E. Sparks \& J. C. Stromberg, 1997. The natural flow regime. Bioscience 47: 769-784.

Poznańska, M., T. Kakareko, M. Krzyżyński \& J. Kobak, 2013. Effect of substratum drying on the survival and migrations of Ponto-Caspian and native gammarids (Crustacea: Amphipoda). Hydrobiologia 700: 47-59.

Pyne, M. I. \& N. L. Poff, 2017. Vulnerability of stream community composition and function to projected thermal warming and hydrologic change across ecoregions in the western United States. Global Change Biology 23: 77-93.

Sprague, L. A., 2005. Drought effects on water quality in the South Platte River Basin, Colorado. Journal of the American Water Resources Association 41: 11-24.

Storey, R., 2016. Macroinvertebrate community responses to duration, intensity and timing of annual dry events in intermittent forested and pasture streams. Aquatic Sciences 78: 395-414.

Strachan, S. R., E. T. Chester \& B. J. Robson, 2014. Microrefuges from drying for invertebrates in a seasonal wetland. Freshwater Biology 59: 2528-2538.

Strachan, S. R., E. T. Chester \& B. J. Robson, 2015. Freshwater invertebrate life history strategies for surviving desiccation. Springer Science Reviews 3: 57-75.

Stubbington, R., 2012. The hyporheic zone as an invertebrate refuge: a review of variability in space, time, taxa and behaviour. Marine and Freshwater Resources 63: 293-311.

Stubbington, R. \& T. Datry, 2013. The macroinvertebrate seedbank promotes community persistence in temporary 
rivers across climatic zones. Freshwater Biology 58: 1202-1220.

Stubbington, R., A. M. Greenwood, P. J. Wood, P. D. Armitage, J. Gunn \& A. L. Robertson, 2009. The response of perennial and temporary headwater stream invertebrate communities to hydrological extremes. Hydrobiologia 630: 299-312.

Stubbington, R., J. Gunn, S. Little, T. P. Worrall \& P. J. Wood, 2016. Macroinvertebrate seedbank composition in relation to antecedent duration of drying and multiple wet-dry cycles in a temporary stream. Freshwater Biology 61: 1293-1307.

Stubbington, R., J. England, P. J. Wood \& C. E. M. Sefton, 2017. Temporary streams in temperate zones: recognizing, monitoring and restoring transitional aquatic-terrestrial ecosystems. WIREs Water 4: e1223.

Vadher, A. N., R. Stubbington \& P. J. Wood, 2015. Fine sediment reduces vertical migrations of Gammarus pulex (Crustacea: Amphipoda) in response to surface water loss. Hydrobiologia 753: 61-71.

Vadher, A. N., C. Leigh, J. Millett, R. Stubbington \& P. J. Wood, 2017. Vertical movements through stream sediment by benthic macroinvertebrates during experimental drying are influenced by sediment characteristics and species traits. Freshwater Biology 62: 1730-1740.

van Vliet, M. T. H. \& J. J. G. Zwolsman, 2008. Impact of summer droughts on the water quality of the Meuse River. Journal of Hydrology 353: 1-17.

Vander Vorste, R., F. Malard \& T. Datry, 2016a. Is drift the primary process promoting the resilience of river invertebrate communities? A manipulative field experiment in an intermittent alluvial river. Freshwater Biology 61: 1276-1292.

Vander Vorste, R., F. Mermillod-Blondin, F. Hervant, R. Mons, M. Forcellini \& T. Datry, 2016b. Increased depth to the water table during river drying decreases the resilience of Gammarus pulex and alters ecosystem function. Ecohydrology 9: 1177-1186.

Vander Vorste, R., F. Mermillod-Blondin, F. Hervant, R. Mons \& T. Datry, 2017. Gammarus pulex (Crustacea: Amphipoda) avoids increasing water temperature and intraspecific competition through vertical migration into the hyporheic zone: a mesocosm experiment. Aquatic Sciences 79: 45-55.

Verdonschot, P. F. M., D. Hering, J. Murphy, S. Jähnig, N. L. Rose, W. Graf, K. Brabec \& L. Sandin, 2010. Climate change and the hydrology and morphology of freshwater ecosystems. In Kernan, M., R. W. Battarbee \& B. R. Moss (eds), Climate Change Impacts on Freshwater Ecosystems. Blackwell Publishing, Oxford: 65-83.

Verdonschot, R. C. M., A. M. van Oosten-Siedlecka, C. J. F. ter Braak \& P. F. M. Verdonschot, 2015. Macroinvertebrate survival during cessation of flow and streambed drying in a lowland stream. Freshwater Biology 60: 282-296.

Whitworth, K. L., D. S. Baldwin \& L. K. Janice, 2012. Droughts, floods and water quality: drivers of severe hypoxic blackwater event in a major river system (the southern MurrayDarling Basin, Australia). Journal of Hydrology 450-451: 190-198.

Wood, P. J., A. J. Boulton, S. Little \& R. Stubbington, 2010. Is the hyporheic zone a refugium for aquatic macroinvertebrates during severe low flow conditions? Fundamental and Applied Limnology 176: 377-390. 